\title{
THE INFLUENCING FACTORS OF INDUSTRIAL CARBON EMISSIONS IN THE CONTEXT OF UNDERTAKING INDUSTRIAL TRANSFER IN ANHUI PROVINCE, CHINA
}

\author{
ZHANG, T. ${ }^{1}$-CHEN, L. Q. ${ }^{1}{ }^{*}-$ WANG, R. ${ }^{2}$-WANG, B. Y. ${ }^{3}-$ LIU, Y. Q. ${ }^{1}$-LIU, W.Q. ${ }^{1}-$ WANG, J. ${ }^{1}$-WEN, M. X. ${ }^{1}$ \\ ${ }^{1}$ School of Environmental Science and Spatial Informatics, China University of Mining and \\ Technology, Xuzhou 221116, China \\ ${ }^{2}$ School of Resources and Geoscience, China University of Mining and Technology, \\ Xuzhou 221116, China \\ ${ }^{3}$ Anhui Province Institute of Land Surveying and Planning, Hefei 230631, China \\ *Corresponding author \\ e-mail: chenlq@cumt.edu.cn \\ (Received $9^{\text {th }}$ Dec 2018; accepted $4^{\text {th }}$ Mar 2019)
}

\begin{abstract}
Industrial development has led to the indisputable fact that high carbon emissions were brought into Anhui Province. This paper calculates the changes in Anhui's carbon emissions from 2000 to 2015 and analyzes the influencing factors. The results prove that carbon emissions show a stable upward trend, but the growth rate has declined after 2005. Carbon emissions produced by three major industrial sectors: mining industry, EGW (electricity, water and gas) and manufacturing industry, show a growing trend, but growth rates decrease successively. According to the STIRPAT model, five factors, including out-of-province investment, energy consumption structure, per capita income, proportion of output value in the secondary industry to GDP and actual use of foreign capital, are positively correlated with Anhui's carbon emissions, while there is a negative correlation between the proportions of the total volume of foreign trade and the industrial added value of enterprises above designated size (two factors) to total industrial output value. As the structure of energy consumption has long been fueled by coal, the transfer of external industry mainly focuses on projects concerning power plants, steel product processing and coal chemical industry, which are highly energy-consuming, which means these are the main factors driving the growth of carbon emissions.

Keywords: industrial carbon emissions, overall change of carbon emission, STIRPAT model, influencing factors, external investment, economic development, energy structure
\end{abstract}

\section{Introduction}

Greenhouse gases, especially carbon dioxide, are regarded as a major cause of global warming, thus becoming a widespread concern (Bamminger et al., 2018), while industries, as the main sources of carbon dioxide emissions, have been the focus of the academic scene (Ban et al., 2016; Rahman and Kashem, 2017; Griffin et al., 2018). As the largest developing country in the world, China has seen its economy maintain rapid development for 40 years since it began its reform and opening-up program in 1978 (Liu et al., 2013, 2014). By this time the country has become one of the world's biggest energy consumers (Deng et al., 2012) and the biggest carbon emitter (Zhang et al., 2015; Shao et al., 2016b). Recent academic researches focus on the following aspects:

\section{Changes in carbon emissions and their spatial distribution during urbanization and industrialization}

Jiang et al. (2018) have discussed the leading factors influencing carbon emissions of China and the U.S. and differences through comparison and analysis of the carbon 
emission processes between the two countries (Jiang et al., 2018). Tian et al. (2011) hold that economic growth, industrial sector and technological changes produce much more carbon dioxide than population, energy structure and other sectors after calculating carbon dioxide emissions of 31 provinces in mainland China and then dividing the 30 provinces (excluding Tibet) into seven groups (Tian et al., 2011). The study of Li et al. (2018) finds that from 2000 to 2013, China's carbon dioxide emissions have grown rapidly, with an average growth rate of $8.2 \%$ ( $\mathrm{Li}$ et al., 2017). Olivier et al. (2015) believe that China accounts for 30\% of total global emissions in 2014, up 80\% from 2004.

In respect to studies on spatial distribution characteristics, Su and Ang (2014) have calculated the total transfer and flow characteristics of embodied carbon emis sions in eight regions of China. Feng et al. (2013) find that $80 \%$ of China's carbon emissions come from economically developed coastal provinces, but since 2003, the carbon emissions have gradually shifted from eastern to western regions, especially in central ones with a huge increase (Meng et al., 2011). Wang et al. (2018c), based on the input-output data in 2007 and 2012, have established an input-output model, evaluate the characteristics of regional carbon flow in China and changes in carbon emissions of different industries and afterwards hold that carbon emissions see a decline from eastern to western regions; by employing a clustering method to evaluate the changes in the growth of carbon emissions in 30 provinces of China from 1996 to 2013, Jiang et al. (2017) hold that the expression of carbon emission intensity varies from province to province so the stages of development of different provinces should be fully considered when the government formulates emission reduction strategies. Zhou et al. (2018) use SDA model to analyze the characteristics of China's regional carbon emissions and transfer, and believe that China's regional carbon emission transfer is mainly completed through carbon-intensive manufacturing industry. Tian et al. (2018) calculate the periodic change of carbon dioxide emissions in China's manufacturing industry from 1992 to 2012 and conclude three main factors leading to the changes in carbon dioxide emissions: carbon emission intensity, input-output structure and final demand. Chen and Yang (2018), based on China's provincial-level panel data from 2006 to 2015, analyze the spatial-temporal evolutionary trend, spatial correlation and influencing factors of China's carbon emissions and find that the characteristics of carbon emission distribution are affected by various economic and social factors. Population pressure, affluence level, energy intensity, industrial structure, urbanization level and fixed asset investment have significant effects on promoting the growth of carbon emissions. Technological level and government environmental regulation play an obvious role in curbing carbon emissions while foreign direct investment (FDI) does not. Liu et al. (2018) analyze the carbon emission efficiency of ten typical urban clusters in China from 2008 to 2015 by setting up the ideal point cross efficiency (IPCE) model and then put forward four carbon emission effects brought by urbanization. Wang and Ma (2018a) study the influencing factors and regional difference of the emission efficiency of expandable industrial carbon dioxide of 13 cities in Jiangsu Province from 2000 to 2014; by analyzing the panel data of the Yangtze River Delta from 2000 to 2010 and the relationship between urbanization and carbon emissions, Li et al. (2018) believe that a u-shaped curvilinear relationship between carbon dioxide emission efficiency and urbanization indicates that carbon dioxide emission efficiency declines at the initial stage of urbanization and goes up when urbanization reaches a higher level. 


\section{Differences of China's regional carbon emissions and their influencing factors}

During the "13th Five-Year Plan" period (2016-2020), China promises that the government will support provincial regions in taking the lead in reaching carbon emission peak value (Shao et al., 2016a). Since 2000, local governments have gradually replaced national ministries and commissions as the main force to implement energy conservation and emission reduction policy (Zhao et al., 2014). China's vast territory and imbalanced social and economic development produce obvious differences in energy consumption, carbon emissions and economic development level in different regions (Wang et al., 2014a; Zhang et al., 2014a), and many scholars begin to pay heed to regional (provincial-level) differences and transfer characteristics of carbon emissions among China's industries. For example, significant differences exist in China's provinces in respect to economic development, industrial structure, energy consumption patterns and other factors (Liu et al., 2013; Shan et al., 2016). Some provinces in eastern China have entered the post-industrial stage, while most of other provinces in central and western China are still at the accelerated stage of industrialization since industry is the main source of GDP for these provinces (Cai et al., 2016; Li et al., 2017; Jia et al., 2018); central and western regions are the major producer and exporter of fossil energy, while most eastern provinces are the main importer of it (Lindner et al., 2013) and in the meantime, some provinces still rely heavily on coal consumption (Wang et al., 2015a).

Consequently, the growth trend of carbon emissions and its driving factors demonstrate the marked features of the differences among provinces in China (Liu et al., 2012a; Guan et al., 2014; Xu et al., 2016). For instance, Su and Ang (2010) analyze the difference in carbon emissions between provinces in China. Meng et al. (2011) find that since 2003, the trend of embodied carbon emissions transfer based on energy products has gradually shifted from eastern to central and western regions, especially in central provinces. Feng et al. (2013) find that 57\% of China's emissions is related to the consumption of goods outside the origin provinces. Western regions produce a large number of low value-added but high carbon-intensive products and export them to eastern regions, leading to a rapid increase in carbon emissions in western regions. Zhang et al. (2014b) analyze carbon dioxide emissions in different provinces of China from 1990 to 2011, and the cross-provincial transfer of carbon emissions in different regions and with different phase characteristics by comparing dioxide emission scale, emission growth rate and emission intensity of different provinces over the years. Sun et al. (2016a) also analyze the characteristics of carbon emission transfer in 30 provinces of China in 2007 and calculate the economic spillover effect and emission reduction effect of cross-provincial carbon emission transfer.

\section{The influencing factors and driving forces of China's carbon emissions}

At present, the research methods on the relationship between economic growth and carbon emissions mainly include Logarithmic Mean Divisia Index (LMDI) (Zhao et al., 2010; Song et al., 2015), panel models (Ren et al., 2014; Zhou et al., 2013), data envelopment analysis (DEA) (Sun et al., 2015b) and Input-Output models (Tian et al., 2014; Mi et al., 2015). Research scale stretches from regions (Lu et al., 2015; Tian et al., 2014) to cities (Mi et al., 2015; Zhao et al., 2010) and industry sectors (Lin and Moubarak, 2014; Lu et al., 2015). 
For example, STIRPAT model is one of the mainstream means used to conduct research on influencing factors of carbon emissions (Waggoner et al., 2002; York et al., 2003). Ma et al. (2017) analyze the driving forces of carbon emissions in China's public construction industry from 2000 to 2015 based on the expanded STIRPAT model. Zhang et al. (2017) analyze the trend of carbon emissions and energy consumption in Henan Province from 1995 to 2014 with STIRPAT model and believe that energy consumption caused by population growth is the major contributor to carbon emissions in the province. Yang et al. (2018a) analyze the impact of the optimized economic structure of Shanghai City on carbon emissions by employing STIRPAT and NSGA-II models. Wang et al. (2018b) analyze the gross scale, structure and influencing factors of household carbon emissions in 30 provinces and regions in China based on the expanded STIRPAT model.

Two commonly used reverse synthesis methods are employed in existing literature (Liu et al., 2012; Xiao et al., 2016): index decomposition analysis (IDA) and structural decomposition analysis (SDA) (Malla, 2009). Both methods have their own advantages and disadvantages. Generally, SDA needs economic data shown in the form of IO table, while IDA only needs the summary data of each industry category (Cansino et al., 2016; Yang et al., 2016). SDA can only analyze changes between finite years, while IDA can usually analyze those between any year (Cellura et al., 2012). Or the study of the decoupling relationship between economic development and carbon emissions can also be conducted. Decoupling relationship analysis mainly adopts OECD decoupling index method (OECD, 2003) and Tapio elastic decoupling index method (Tapio, 2005). The objects of decoupling relationship analysis are diversified, which can be analyzed from a macro to micro perspective. For example, Yu et al. (2013) employ OECD decoupling model to study the decoupling relationship between carbon dioxide, sulfur dioxide, dust, sewage discharge and economic development in China from 1978 to 2010. Wang et al. (2015c), Zhang and Wang (2013) and Wang et al. (2015b) employ Tapio decoupling model to study the decoupling relationship between the economic development in Tianjin, Jiangsu Provinces and Beijing-Tianjin-Hebei region and pollutant emissions, featuring carbon dioxide. Wang et al. (2014b) combine Tapio decoupling model with LMDI decomposition model to analyze the decoupling situation between China's economic growth and energy consumption from 1991 to 2011.

\section{Study on the impact of changes in industrial structure and industrial transfer on carbon emissions}

Industrialization is the dominant driving force of China's economic growth and energy consumption growth. From 1985 to 2011, energy consumption in China's industrial sectors accounts for $70.3 \%$ of total energy consumption, showing an upward trend year by year. Energy conservation and emission reduction in China's industrial sectors are the key to China's emission reduction and successful low-carbon transition (Ouyang and Lin, 2015). Carbon emissions, industrial structure change and transfer of different industries in China have gradually become a research field with high attention (Auerbeck, 2001; Lebel et al., 2007). For example, Su et al. (2010) employ input-output analysis framework to analyze industrial agglomeration effect in China and estimate carbon dioxide emissions reflected in economic exports. Yan and Fang (2015) study the historical track, characteristics and influencing factors of carbon emissions in China's manufacturing industry from 1993 to 2011. Cheng et al. (2018) set up total-factor carbon emission efficiency index (TCEI) by employing improved NDDF model and 
estimate the meta-frontier TCEI index of 30 provincial industrial sectors in China from 2005 to 2015. They hold that industrial meta-frontier TCEI in China is relatively low and many provinces still have large room for improving the industrial TCEI. Xian et al. (2018), taking China's electric power industry as an example, put forward a scenario analysis on whether China's electric power industry could achieve the goal of reducing national and provincial-level carbon dioxide emission intensity from 2016 to 2020 by analyzing changes in carbon productivity. Zhao et al. (2017) analyze the decoupling relationship of China's economic growth based on the carbon emissions in five economic sectors, including agriculture and industry.

Some scholars conduct studies on industrial carbon emissions through modeling. For example, Yang et al. (2018a) analyze the relationship between energy consumption and carbon emissions in different industrial sectors in Zhejiang Province from 1995 to 2014 by employing STIRPAT model. Zhang et al. (2017) analyze the influencing factors of carbon emissions in China's construction industry with factor analysis and STIRPAT model. Lindner et al. (2013) employ a bottom-up model to calculate the direct carbon embodied in China's power industry. Zhao et al. (2010) analyze the influencing factors of industrial carbon emissions of Shanghai with LMDI model.

On the other hand, with the development of China's economy, a large number of traditional industries are constantly shifting to central and western regions (Chen et al., 2011; Tian et al., 2014) and industrial transfer, mainly occurring in manufacturing sector, brings the transfer of carbon emissions (Yuan et al., 2009). These studies provide numerous useful information but limitations remain instead. For example, most studies focus on the overall and cross-provincial carbon transfer in China, but existing studies lack of consideration about the inter-industry carbon transfer and leading factors. In addition, most studies only center on short-term changes and lack long-term dynamic studies.

Anhui Province is an underdeveloped province in central China, but it is the main area carrying on industrial transfer in the Yangtze River Delta for being close to the Yangtze River Delta region which is the most economically developed in the country. Although a large number of studies have examined the rapid growth of Anhui's carbon emissions and its influencing factors (Zhang and Wang, 2013), existing studies rarely consider the specific impact of industrial transfer and structural change on Anhui's carbon emissions. Leading industries and technological capabilities vary from region to region, leading to different emission intensity in industrial sectors and there may be differences in the characteristics of carbon dioxide emissions (Tian et al., 2012). At the same time, if the decoupling relationship at the provincial level is not fully understood, the implementation effect of national policies or strategies will decline (Liu et al., 2015). Therefore, only the relationship between industrial transfer and carbon emissions can help to formulate an effective energy conservation and carbon emission reduction policy. Taking Anhui Province as a case study, this paper calculates Anhui's carbon emission model by collecting data of energy consumption and social development in Anhui Province from 2000 to 2015, and employs expanded STRIPAT model to reveal the changes in industrial carbon emissions and its influencing factors in the province in the context of industrial transformation. This study helps to understand the driving factors of industrial carbon emissions in Anhui Province and on that basis, provides reference for reducing industrial carbon emissions. 


\section{Materials and methods}

\section{Study area and data}

Anhui Province is included in the case study hereof. Located in mid-eastern China, Anhui covers an area of $140,100 \mathrm{~km}^{2}$ and has 14 prefecture-level cities under its jurisdiction, with a population of 70.27 million in 2016 and an urbanization rate of $52.0 \%$. According to the date of Statistical Bureau of Anhui province (2017), Anhui is in the bottom half of national list of economic development as it ranks 13th among 31 Chinese provinces in GDP growth (from RMB 290.209 billion yuan in 2000 to RMB $2,411.789$ billion yuan in 2016 , growing by $14.15 \%$ annually), and ranks 25 th in per capita GDP growth (from RMB 4,800 yuan in 2000 to RMB 39,100 yuan in 2016, growing by $14.04 \%$ annually). Anhui economy is dominated by the secondary industry, which accounted for $36.41 \%$ of the provincial GDP in 2000, and for about half $(48.06 \%)$ in 2016 , and its second industry is dominated by the Industry, which accounted for $30.04 \%$ of the output of second industry in 2000 , and this increased to $40.82 \%$ in 2016. These indicate that Anhui is still at the mid stage of industrialization, where its economic development is mainly driven by the Industry. Anhui is a close neighbor of Yangtze River Delta (Fig. 1), the powerhouse for China's economy, and a critical base for implementation of the state strategy of rise of central China and industrial transference to Wanjiang City Belt, which is a contributor to carbon emission, therefore this study focuses on the carbon emission by Anhui's Industry that can be divided, according to Industrial Classification for National Economic Activities (GB/T 4754-2002), into mining, manufacturing and EGW (electricity, gas and water). End-use energy consumption, GDP, added value of industries above a designated scale, total industrial output, total external fund used (including investment from foreign countries, Hong Kong, Macao and Taiwan), output value of secondary industry, population and per capita income are all sourced from China Energy Statistical Yearbook and Anhui Province Statistical Yearbook, and the data of external investment are from the public data released by Anhui Development and Reform Commission (Anhui Statistical Bureau, http://www.ahpc.gov.cn/).

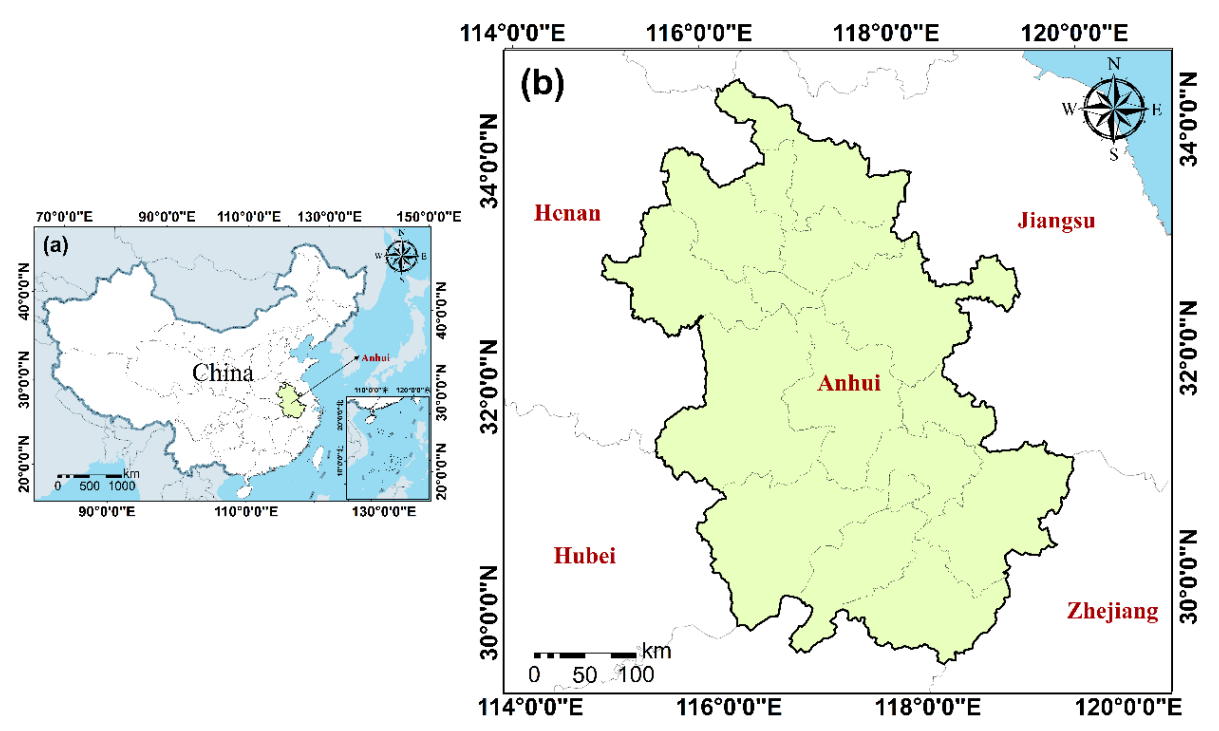

Figure 1. Location of Anhui province 


\section{Methods}

\section{Calculation of carbon emission}

Given that no direct data of $\mathrm{CO}_{2}$ emission is released by China's statistical organizations, scholars at home and abroad generally make estimation by multiplying the energy consumption with carbon emission coefficient, therefore the industrial carbon emission of Anhui 2000-2005 is calculated by the following model (Yang et al., 2018):

$$
\mathrm{c}=\sum E_{j} \times F_{j}
$$

where, and signify the consumption and emission coefficient of $\mathrm{j}$ kinds of fossil fuels respectively. The standard coal conversion coefficient in China Energy Statistical Yearbook is adopted, while the emission coefficient is converted based on the statistics of Peng et al. (2013) (see Table 1).

Table 1. Conversion coefficients (by Peng et al., 2013)

\begin{tabular}{c|c|c}
\hline Types of energy & Standard coal conversion coefficient & Carbon emission factor \\
\hline Raw coal & $0.7143 \mathrm{~kg} \cdot \mathrm{kg}^{-1}$ & 0.7599 \\
Washed coal & $0.9 \mathrm{~kg} \cdot \mathrm{kg}^{-1}$ & 0.7599 \\
liquefied petroleum gas & $1.7143 \mathrm{~kg} \cdot \mathrm{kg}^{-1}$ & 0.5042 \\
Crude oil & $1.4286 \mathrm{~kg} \cdot \mathrm{kg}^{-1}$ & 0.5847 \\
Gasoline & $1.4714 \mathrm{~kg} \cdot \mathrm{kg}^{-1}$ & 0.5538 \\
kerosene & $1.4714 \mathrm{~kg} \cdot \mathrm{kg}^{-1}$ & 0.5714 \\
Diesel & $1.4571 \mathrm{~kg} \cdot \mathrm{kg}^{-1}$ & 0.5921 \\
Fuel oil & $1.4286 \mathrm{~kg} \cdot \mathrm{kg}^{-1}$ & 0.6185 \\
Coke & $0.9714 \mathrm{~kg} \cdot \mathrm{kg}^{-1}$ & 0.855 \\
Gas field & $1.2143 \mathrm{~kg} / \mathrm{m}^{3}$ & 0.4483 \\
Oil field natural gas & $1.33 \mathrm{~kg} / \mathrm{m}^{3}$ & 0.4483 \\
Coke oven gas & $0.5714 \mathrm{~kg} / \mathrm{m}^{3}$ & 0.3548 \\
\hline
\end{tabular}

\section{STIPRAT model}

STIRPAT model was built by York et al. (2003) based on IPAT model, with the following formula:

$$
\mathrm{I}=\mathrm{a} P^{b} A^{c} T^{d} e
$$

where, I stands for environmental stress, $\mathrm{P}$ for population size, A for affluence, $\mathrm{T}$ for technical progress, a for the model efficient, b, c, d are the indexes of respective independent variables, and e is the model's error term. b, c and d are introduced to make up for the model's deficiency of I varies with all driving factors in proportion, and can be used for analysis of independent variables' non-proportional impact on environmental stress. After logarithm the model can be converted to:

$$
\ln I=\ln a+b \ln P+\operatorname{cln} A+d \ln T+\ln e
$$


where, $\mathrm{b}, \mathrm{c}$ and $\mathrm{d}$ embody the elastic relation between independent and dependent variables. Every $1 \%$ change of $\mathrm{P}, \mathrm{A}$ or $\mathrm{T}$ will result in $\mathrm{b} \%, \mathrm{c} \%$ or $\mathrm{d} \%$ change of environment impact.

As the regional industrial structure is changed and carbon emission affected by input of extern fund (Chen et al., 2017) during local industrial transference, to truthfully reflect such transference's impact on carbon emission, STIRPAT model for this study is hereby extended as:

$$
\ln I=\ln B+\alpha_{1} \ln X_{1}+\alpha_{2} \ln X_{2}+\alpha_{3} \ln X_{3}+\alpha_{4} \ln X_{4}+\alpha_{5} \ln X_{5}+\alpha_{6} \ln X_{6}+\alpha_{7} \ln X_{7}+\operatorname{lne} \text { (Eq.4) }
$$

where, I signifies the industrial emission, B is the model coefficient and e its error term. There are 7 variables in 5 categories: the factor that embodies the effect of industrial agglomeration, namely $\mathrm{X} 1$ - the ratio of the added value of industries above a designated scale to total industrial output value; the 2 factors that embody external capital scale in industrial transference, namely total external fund used $\mathrm{X}_{2}$ and total external investment $X_{7}$; the 2 factors that indicate economic growth, namely $X_{3}-$ the proportion of secondary industry in GDP and $\mathrm{X}_{4}$ - per capita income; $\mathrm{X}_{5}$ - proportion of coal consumption in total energy consumption, the factor that reflects the energy structure; $\mathrm{X}_{6}$ - the proportion of total import-export volume in total industrial output value and $\alpha_{\mathrm{i}}$, the elastic coefficients of independent variables, which mean $1 \%$ variation of $\mathrm{X}_{\mathrm{i}}$ can result in $\alpha_{\mathrm{i}} \%$ change of carbon emission.

\section{Results}

\section{Anhui's industrial carbon emission}

\section{Overall change of carbon emission}

Figure 2 shows that, from 2000 to 2015, the value of industrial output and carbon emission in Anhui grew annually by $15.26 \%$ and $10.50 \%$ respectively, but the 2010 2015 period saw such growths of $11.37 \%$ and $4.29 \%$ only. The change indicates that Anhui made some achievements in low-carbon transition and restructuring of its industries during the $12^{\text {th }}$ five-year plan, and the rapid growth of carbon emission was more or less contained.

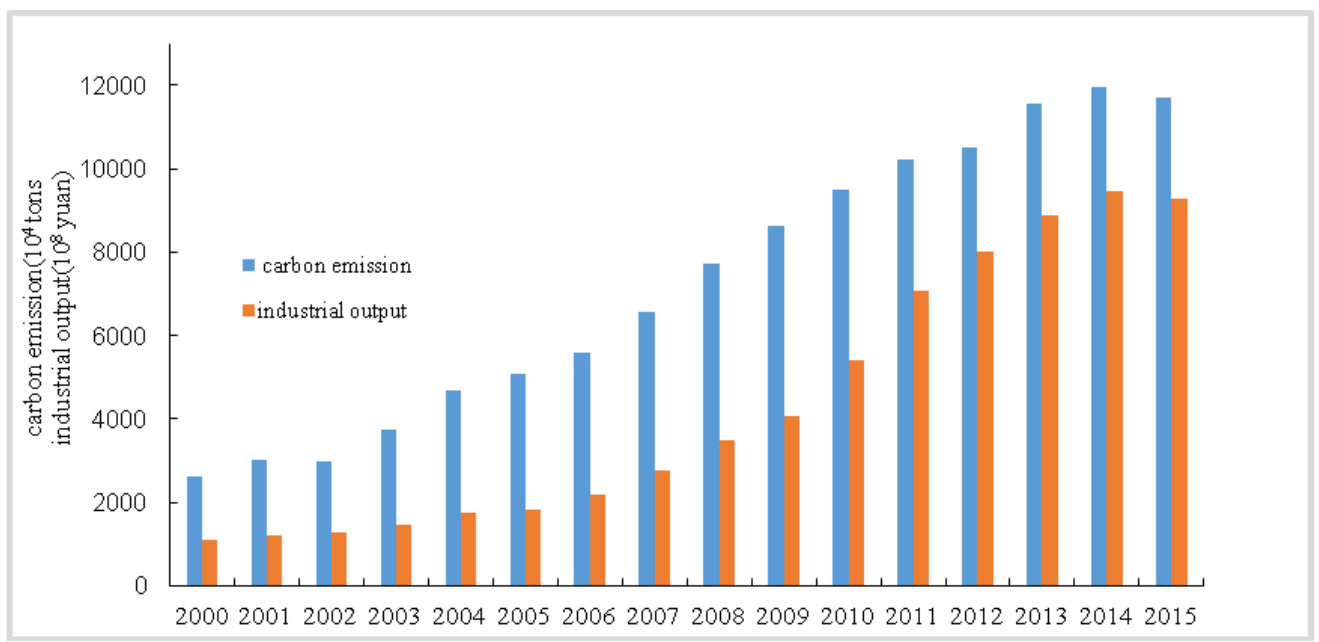

Figure 2. Change of carbon emissions, industrial production of Anhui province (2000-2015) 


\section{Change of carbon emission for different industries}

(1) In general, 2000-2015 saw increase of carbon emission in indusries of mining, manufacturing and EGW. In growth rate mining > EGW > manufacturing (slope: 217.35, 265.53 and 221.26) (Fig. 3), and the trend differs greatly among these three sectors: for manufacturing, the annual growth of carbon emission stood at $11.05 \%$ between 2000 and 2005, but by $7.43 \%$ only in the period 2005-2014, and this figure further deceased from 2014; For EGW, the carbon emission grew stably by $12.73 \%$ annually from 2000-2015, and only from 2015 this growth slowed down. Compared with EGW and manufacturing, mining is at a stage of relatively faster growth, for its growth of carbon emission reached a high level of $19.49 \%$ between 2000 and 2005, decreased somehow from 2005 to 2014 , but the $12.78 \%$ growth rate was still high.

(2) As of proportions of these three industries, the proportion of manufacturing in carbon emission has been decreasing stably. Though EGW saw some narrow marked fluctuation, its proportion is considered stable in long term (about 30\%). While the proportion of mining had been rising, its growth rate gradually dropped and reached a plateau after 2010. Figure 4 shows that in general, the propotions of the three industries all tend to converge to the size of "one third".

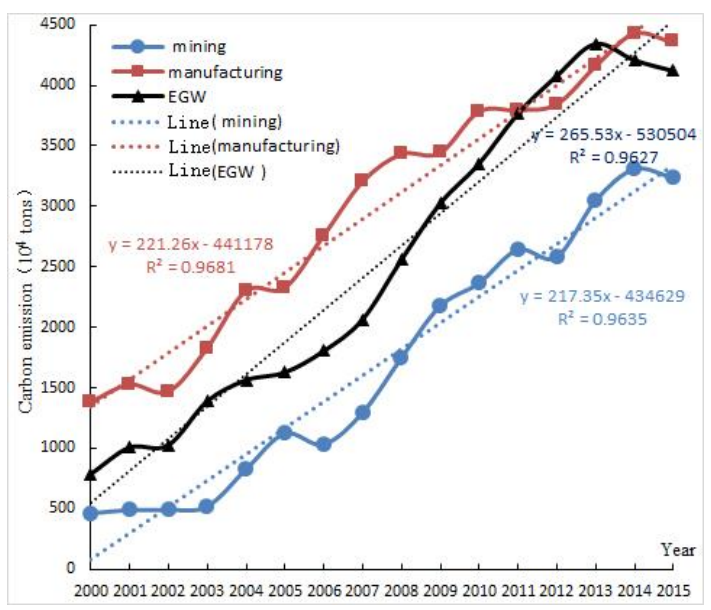

Figure 3. Change of carbon emissions of Anhui's three industrial sectors (2000-2015)

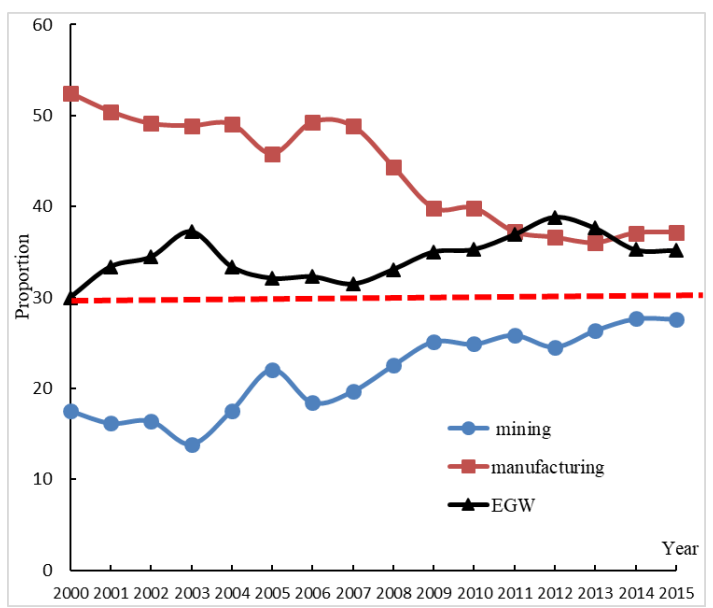

Figure 4. Change of carbon emission share of Anhui's three industrial sectors (2000-2015) 


\section{Calculation results with STIRPAT model}

7 factors, namely the proportion of the added value of industries above a designated scale in total industrial output value $\left(\mathrm{X}_{1}\right)$, total external fund used $\left(\mathrm{X}_{2}\right)$, the proportion of secondary industry in GDP $\left(\mathrm{X}_{3}\right)$, per capita income $\left(\mathrm{X}_{4}\right)$, energy consumption structure (proportion of coal consumption in total energy consumption) $\left(\mathrm{X}_{5}\right)$, the proportion of total import-export volume in total industrial output value $\left(\mathrm{X}_{6}\right)$ and total external investment $\left(\mathrm{X}_{7}\right)$, are selected for regression analysis with SPSS (a statistical analysis software), to reveal their marginal contribution to carbon emission.

In the first place, least square regression model is used in SPSS for pre-evaluation (Table 2). The least square regression model has a fitting goodness of fit $\mathrm{R}^{2}=0.995$, and an adjusted goodness of fit $\operatorname{Adj}^{2}=0.991$, both of which pass the $F$ test of 0.001 significant level, indicating that the linear model for independent and dependent variables exists and has a high degree of fitting. But only $\mathrm{LnX}_{1}$ passes the Student's $\mathrm{t}$ test ( $t$ test) of 0.005 significant level, and other independent variables fail to pass the significance test (Sig). A study of the correlation matrix of the model shows that the independent variables are closely associated with each other. Variance inflation factor (VIF) is currently used for determination of multiple correlation, while the VIF values of 6 factors calculated are all greater than 10, therefore only when the multicollinearity among independent variables are eliminated can robust results be achieved.

Table 2. Results of the OLS (ordinary least square) regression model

\begin{tabular}{|c|c|c|c|c|c|c|}
\hline & \multicolumn{2}{|c|}{ Unnormalized coefficient } & \multirow[b]{2}{*}{$\begin{array}{l}\text { Regression } \\
\text { coefficient }\end{array}$} & \multirow[b]{2}{*}{ T test } & \multirow[b]{2}{*}{ Significance } & \multirow{2}{*}{$\begin{array}{c}\text { Variance } \\
\text { inflation } \\
\text { factor }\end{array}$} \\
\hline & $\begin{array}{l}\text { Regression } \\
\text { coefficient }\end{array}$ & $\begin{array}{l}\text { Standard } \\
\text { error }\end{array}$ & & & & \\
\hline $\begin{array}{l}\text { Independent } \\
\text { variable }\end{array}$ & -2.455 & 2.157 & & -1.138 & 0.288 & \\
\hline $\operatorname{LnX}_{1}$ & 0.589 & 0.345 & 0.124 & 1.708 & 0.126 & 9.05 \\
\hline $\mathrm{LnX}_{2}$ & -0.086 & 0.049 & -0.201 & -1.74 & 0.12 & 22.859 \\
\hline $\mathrm{LnX}_{3}$ & 0.307 & 0.327 & 0.116 & 0.939 & 0.375 & 26.204 \\
\hline $\mathrm{LnX}_{4}$ & 0.939 & 0.251 & 1.242 & 3.738 & 0.006 & 189.191 \\
\hline $\operatorname{LnX}_{5}$ & -1.378 & 1.836 & -0.073 & -0.751 & 0.474 & 16.08 \\
\hline $\operatorname{LnX}_{6}$ & -0.058 & 0.201 & -0.039 & -0.287 & 0.781 & 31.123 \\
\hline $\operatorname{LnX}_{7}$ & -0.016 & 0.105 & -0.026 & -0.156 & 0.88 & 47.071 \\
\hline
\end{tabular}

Partial least square regression model (PLS) is used to address the practical problems of multiple correlations of variables, small sample volume and low degree of freedom, in an analytical process of:

(1) Standardized processing of variables, to rid of the dimensional effects among variables and make them comparable, and the processed data are expressed as $Z \mathbf{L n X}{ }_{1}$, $\mathrm{ZLnX}_{2}, \mathrm{ZLnX}_{3}, \mathrm{ZLnX}_{4}, \mathrm{ZLnX}_{5}, \mathrm{ZLnX}_{6}, \mathrm{ZLnX}_{7}$ and ZLnC.

(2) Principal components are extracted from data processed in procedure (1), refer to Table 3 for the results.

Table 3 shows that the accumulative contribution of $\mathrm{FAC}_{1}, \mathrm{FAC}_{2}$ and $\mathrm{FAC}_{3}$ reaches a high level of $95.602 \%$, so 2 principal components are extracted. Table 4 indicates the following relations between $\mathrm{FAC}_{1}, \mathrm{FAC}_{2}$ and original variables: 


$$
\begin{aligned}
\mathrm{FAC}_{1}= & -0.142 \times \mathrm{ZLnX}_{1}+0.155 \times \mathrm{ZLnX}_{2}+0.155 \times \mathrm{ZLnX}_{3}+0.157 \\
& \times \mathrm{ZLnX}_{4}+0.149 \times \mathrm{ZLnX}_{5}-0.148 \times \mathrm{ZLnX}_{6}+0.145 \times \mathrm{ZLnX}_{7} \\
\mathrm{FAC}_{2}= & 1.053 \times \mathrm{ZLnX}_{1}+0.052 \times \mathrm{ZLnX}_{2}+0.114 \times \mathrm{ZLnX}_{3}+0.25 \\
& \times \mathrm{ZLnX}_{4}+0.529 \times \mathrm{ZLnX}_{5}+0.78 \times \mathrm{ZLnX}_{6}+0.829 \times \mathrm{ZLnX}_{7}
\end{aligned}
$$

Table 3. Results of the principal component analysis

\begin{tabular}{c|c|c|c|c|c|c}
\hline \multirow{2}{*}{ Component } & \multicolumn{3}{|c|}{ Initial eigenvalues } & \multicolumn{3}{c}{ Sums of squared loadings } \\
\cline { 2 - 7 } & Total & Variance \% & Cumulative \% & Total & Variance \% & Cumulative \% \\
\hline 1 & 6.33 & 90.433 & 90.433 & 6.33 & 90.433 & 90.433 \\
2 & 0.362 & 5.169 & 95.602 & 0.362 & 5.169 & 95.602 \\
3 & 0.189 & 2.694 & 98.297 & 0.189 & 2.694 & 98.297 \\
4 & 0.046 & 0.652 & 98.949 & & & \\
5 & 0.038 & 0.547 & 99.496 & & & \\
6 & 0.031 & 0.447 & 99.944 & & & \\
7 & 0.004 & 0.056 & 100 & & & \\
\hline
\end{tabular}

Table 4. Coefficient matrix for each component

\begin{tabular}{l|c|c}
\hline & \multicolumn{2}{|c}{ Component } \\
\cline { 2 - 3 } & $\mathbf{1}$ & $\mathbf{2}$ \\
\hline Zscore $\left(\mathrm{X}_{1}\right)$ & -0.142 & 1.053 \\
$\mathrm{Zscore}\left(\mathrm{X}_{2}\right)$ & 0.155 & 0.052 \\
$\mathrm{Zscore}\left(\mathrm{X}_{3}\right)$ & 0.155 & 0.114 \\
$\mathrm{Zscore}\left(\mathrm{X}_{4}\right)$ & 0.157 & 0.25 \\
$\mathrm{Zscore}\left(\mathrm{X}_{5}\right)$ & 0.149 & 0.529 \\
$\mathrm{Zscore}\left(\mathrm{X}_{6}\right)$ & -0.148 & 0.78 \\
$\mathrm{Zscore}\left(\mathrm{X}_{7}\right)$ & 0.145 & 0.829 \\
\hline
\end{tabular}

(3) OLS (Ordinary Least Square) regression analysis of principal components and total carbon emission

Least square regression analysis is conducted with ZLnC as the dependent variable, $\mathrm{FAC}_{1}$ and $\mathrm{FAC}_{2}$ as the independent variables, fitting goodness of fit $\mathrm{R}^{2}=0.994$, $\mathrm{F}=313.486, \mathrm{t}$ test $\mathrm{Sig}<0.01$, which indicate a good model fitting. Refer to Tables 5 and 6 for the results of variance analysis and model coefficient respectively.

Table 5. Results of analysis of variance

\begin{tabular}{c|c|c|c|c|c}
\hline & Quadratic sum & Degrees of freedom & Standard deviation & F test & Significance \\
\hline Regression & 14.695 & 2 & 7.348 & 313.486 & 0 \\
Residual error & 0.305 & 13 & 0.023 & & \\
Total & 15 & 15 & & & \\
\hline
\end{tabular}


Table 6. Model coefficients

\begin{tabular}{c|c|c|c|c|c}
\hline & \multicolumn{2}{|c|}{ Unstandardized coefficients } & $\begin{array}{c}\text { Regression } \\
\text { coefficient }\end{array}$ & T test & Significance \\
\cline { 2 - 5 } & Regression coefficient & Standard error & & $-7.00 \mathrm{E}^{-14}$ & 1 \\
\hline Constant & $-2.68 \mathrm{E}^{-15}$ & 0.038 & 0.981 & 24.829 & 0 \\
FAC1_2 & 0.981 & 0.04 & 0.128 & 3.239 & 0.006 \\
\hline FAC2_2 & 0.128 & 0.04 & & & \\
\hline
\end{tabular}

The following equation between dependent variable ZLnC and principal components $\mathrm{FAC}_{1}$ and $\mathrm{FAC}_{2}$ can be formed when regression coefficient in Table 6's model is adopted, where constant term is deleted for the Sig value of its test $=1$, and Sig values of regression coefficient $\mathrm{t}$ test for $\mathrm{FAC}_{1}$ and $\mathrm{FAC}_{2}$ are less than 0.01 , therefore this model has high authenticity.

$$
\mathrm{ZLnC}=0.981 \times \mathrm{FAC}_{1}+0.128 \times \mathrm{FAC}_{2}
$$

Based on standardization formula and standardized variables described in Table 2, the above formula can be converted into:

$$
\begin{aligned}
\ln C=- & 0.0045 \times \operatorname{Ln} X_{1}+0.1587 \operatorname{Ln} X_{2}+0.1666 \times \operatorname{Ln} X_{3}+0.186 \\
& \times \operatorname{Ln} X_{4}+0.2139 \times \operatorname{Ln} X_{5}-0.0453 \operatorname{Ln} X_{6}+0.2484 \times \operatorname{Ln} X_{7}
\end{aligned}
$$

The final results are as follows:

$$
\mathrm{C}=\mathrm{X}_{1}^{-0.0045} \mathrm{X}_{2}^{0.1587} \mathrm{X}_{3}^{0.1666} \mathrm{X}_{4}^{0.186} \mathrm{X}_{5}^{0.2139} \mathrm{X}_{6}^{-0.0453} \mathrm{X}_{7}^{0.2484}
$$

The above formula shows that, among the driving factors that affect Anhui's carbon emission 2000-2015, 5 are positively correlated, but in degree of influence, external investment > energy consumption structure > per capita income > proportion of secondary industry in GDP > total external fund used. Only 2 factors, namely the proportion of total import-export volume in total industrial output value and the proportion of the added value of industries above a designated scale in total industrial output value are negatively associated with the total carbon emission, but far less influential than the other 5 positively correlated factors.

\section{Discussion}

\section{Economic development and carbon emissions}

According to previous studies (Yang et al., 2018), there are three inverted U-shaped curves (Fig. 5) during the evolution of the relationship between economic development and carbon emissions, namely inverted U-shaped curves of carbon emissions, per capita carbon emissions and carbon emission amount. Specifically, during the evolution process, three curves need to cross their peaks respectively, namely the peaks of the inverted U-shaped curves of carbon emission intensity, per capita carbon emissions and carbon emission amount. During the evolution, dominant driving forces of carbon 
emissions vary from stage to stage. In the period before carbon emission intensity peaks, energy and advance in carbon-intensive technology are the main influencing factors; from the peak of carbon intensity to that of per capita carbon emission amount, economic growth is the main influencing factor; from the peak of per capita carbon emission amount to that of carbon emission amount, advance in carbon emission reduction technology is the main influencing factor but it plays a decisive role after entering the stage in which total carbon emissions decline steadily. As shown in Figure 6, Anhui Province's carbon emission intensity reaches its peak in 2005, indicating that energy and carbon-intensive technology advance are the main influencing factors for the growth of carbon emissions before 2005, which is mainly caused by the law of economic development of Anhui Province. Apart from the fact that main economic development remains in the middle stage of accelerated industrialization, Anhui Province (an important area producing coal and iron ore in Central China) has an advanced mining industry in the industrial structure, and most of the industrial types are supported by coal as their main energy and technologies relatively lag behind, so energy and carbon-intensive industries are the important influencing factors for the growth of carbon emissions in this period; from 2005 to 2015, Anhui's carbon intensity continues to decline but per capita carbon emissions keep rising, indicating that economic growth is the leading factor influencing the growth of carbon emissions during the period from 2005 to 2015. This is the golden period for Anhui to take advantage of the industrial transfer, with a large number of foreign capital and traditional industries in the Yangtze River Delta region transferring to Anhui, resulting in rapid industrial growth and further promoting the growth of carbon emissions. It can also be found from the calculation results of STIRPAT model established in this paper that the importance of three coefficients, namely the total amount of out-of-province investment, per capita income and the total amount of actual use of foreign capital, rank the first, third and fifth in positive correlation, which further proves the significance of economic development in carbon emissions. It can be predicted that when the per capita carbon emissions of Anhui Province peak, advance in carbon emission reduction technology will become the main factor influencing the growth of carbon emissions.

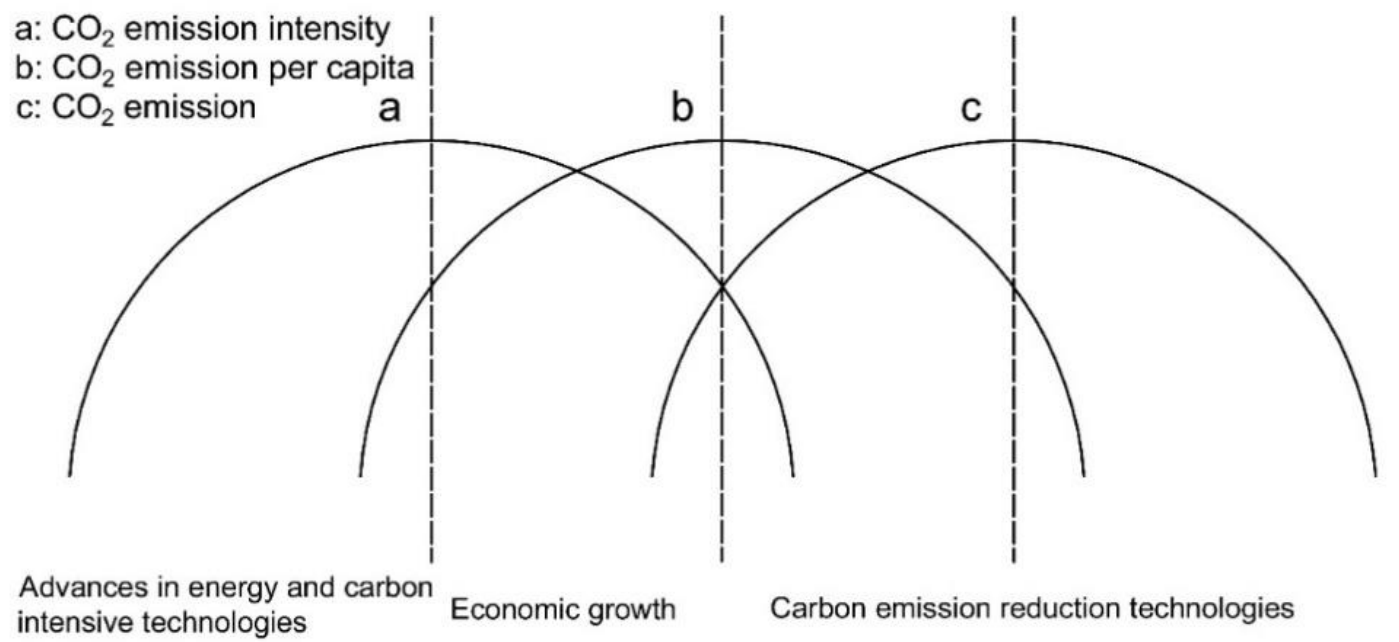

Figure 5. Three inverted $U$ curves rule of economic development and $\mathrm{CO}_{2}$ emissions 


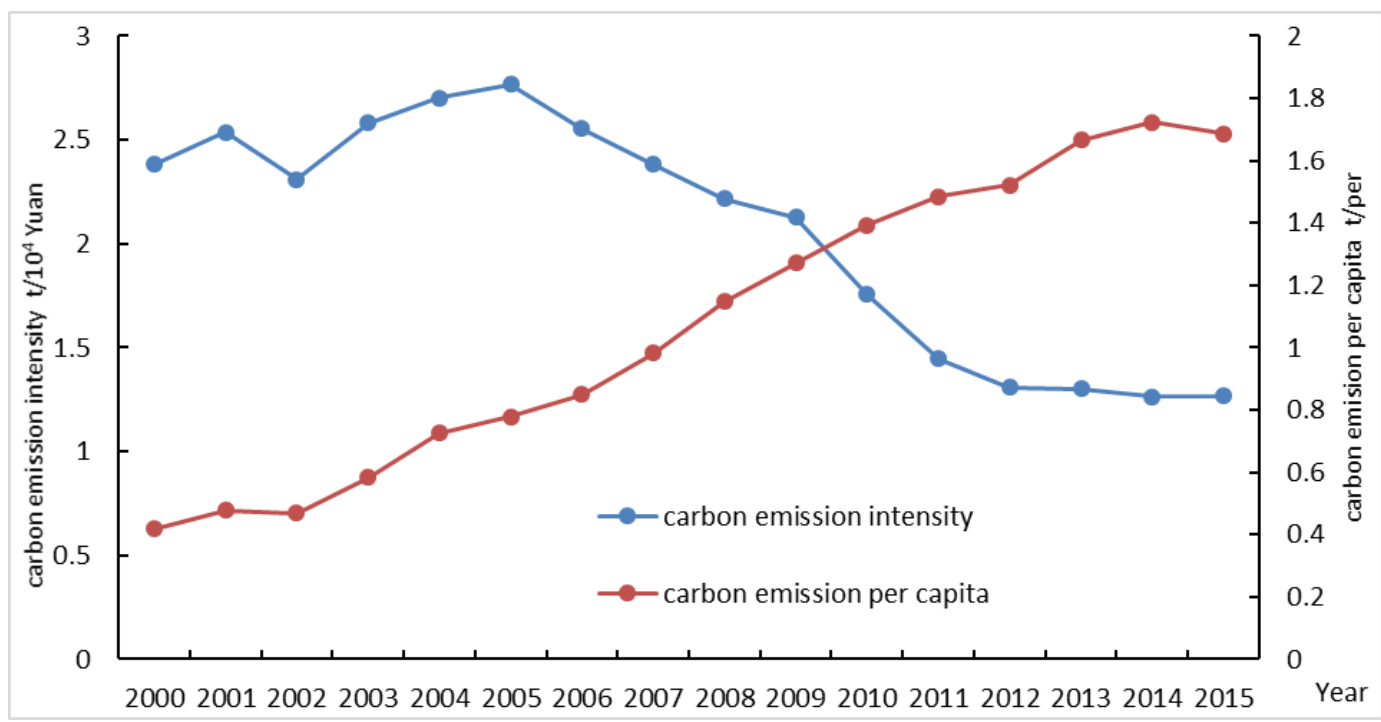

Figure 6. Change of carbon emission intensity and carbon emission per capita of Anhui province (2000-2015)

It is worth noting that compared with neighboring developed provinces such as Zhejiang and Jiangsu, Anhui shows an obvious lagged relationship between economic development and carbon emissions. For example, Zhejiang Province has reached the peak of carbon emission intensity as early as 1995 (Yang et al., 2018) and that of Jiangsu has also peaked in 2000 (Zhu et al., 2018). It also reflects that after Zhejiang and Jiangsu implement industrial upgrading and technological transformation, a large number of backward industries move out, thus promoting the reduction in carbon emission intensity. However, as the major industrial undertaking area of the two provinces, Anhui sees an increase in carbon emissions instead, forming a "pollution haven effect".

\section{Energy structure and carbon emissions}

In respect to energy consumption structure, the ratio of coal consumption to total energy promotes the growth of carbon emissions, and the ratio increases by $1 \%$ and carbon emission amount will increase by $0.2139 \%$. For a long period of time, fossil energy has been the major resource consumed in Anhui Province, especially coal, which occupies a dominant and gradually consolidated position. The proportion of coal consumption to fossil energy consumption rises from $90.57 \%$ in 2000 to $96.08 \%$ in 2015 (Fig. 7), coal consumption share is $14 \%$ higher than the national average and nonfossil energy consumption share is $8.8 \%$ lower than the national average. The pressure to reduce the proportion of fossil energy consumption is particularly obvious in the context of China's increasing emphasis on energy conservation and emission reduction as a way to tackle climate change. There are two main reasons for why coal consumption outshine others: one is the resource endowment of Anhui Province. It has abundant coal resources and is a major coal producer but lacks oil and natural gas, being a typical province with "rich coal but no oil and gas". In comparison, the coal consumption has taken a dominant position in the province for a long time for its prominent convenience for coal consumption and price advantage; the other is its advanced industrial structure in heavy chemical industries in respect to power, chemical 
industry and steel for the long-term use of coal, which further deepens its dependence on coal, leading to a large demand for the resource. For example, existing research has shown that in 2011, carbon emissions in Anhui's manufacturing industry mainly comes from ferrous metal smelting and rolling processing industry (37.4\%-37.9\%), nonmetallic mineral products industry (28.9\%-29.8\%), chemical raw materials and products manufacturing industry (14.3\%-14.5\%), petroleum processing and coking and nuclear fuel processing industry (9.8\%-10.0\%). Employees in these four industries account for $18 \%$ of the total in industry, the proportion to total industrial added value is not more than 1/4 but carbon emissions are more than $90 \%$ (Shen et al., 2018). According to the goals of the Outline of the 13th Five-Year Plan for National Economic and Social Development of Anhui Province and China's 13th Five-Year Plan for Energy Development, by 2020, provincial demand for primary energy consumption will have been limited to 142 million tons of standard coal, non-fossil energy consumption accounted for $5.5 \%$ of total energy consumption and the proportion of coal consumption dropped below $75 \%$. The pressure to cut coal capacity remains heavy, which needs to be brought to the forefront.

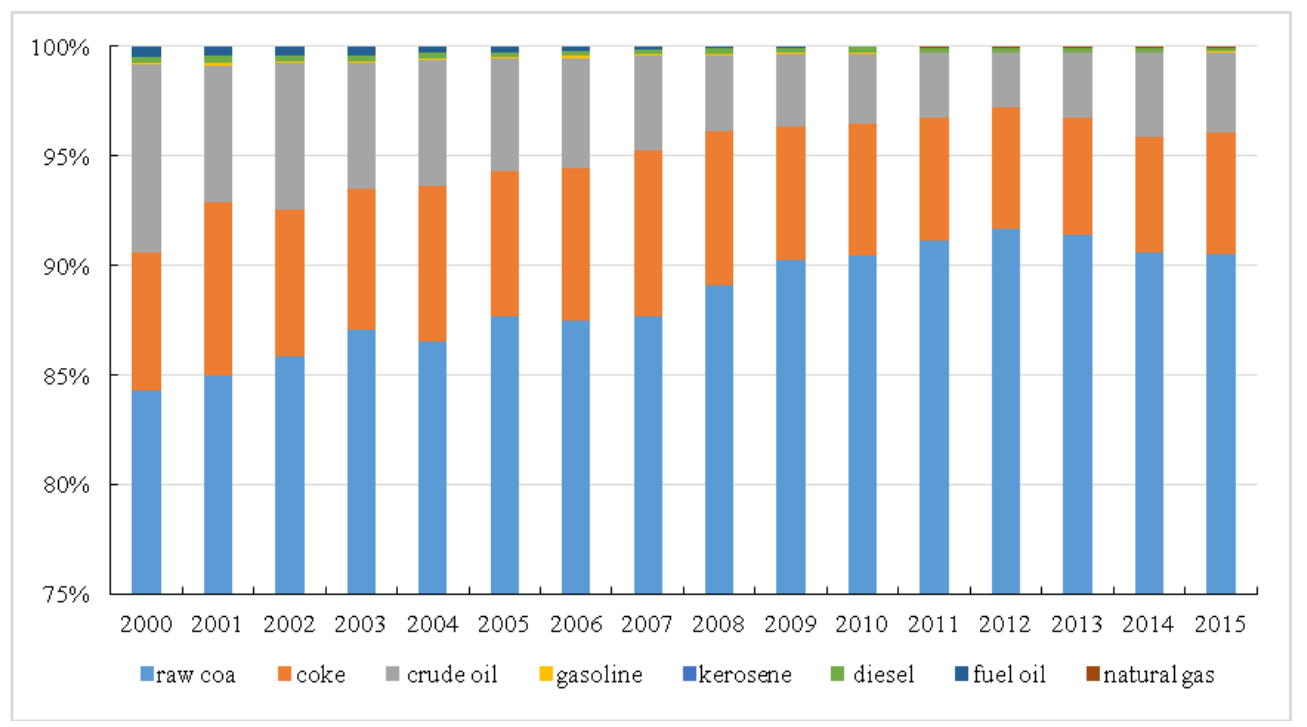

Figure 7. Change of energy consumption structure changes of Anhui province (2000-2015)

\section{Industrial agglomeration and carbon emissions}

A large number of studies at home and abroad have shown that industrial agglomeration has certain promoting significance for China's carbon emission reduction (Wang et al., 2013). Industrial agglomeration mainly affects carbon emission intensity through scale effect, technology effect and competition effect: firstly, industrial agglomeration can bring scale effect and realize the free flow of production factors within the cluster range so as to improve energy utilization efficiency; secondly, industrial agglomeration can promote the concentration and close connection of industries with upstream and downstream relations in geographical space, so as to save costs such as that of raw materials and transportation, and thus reduce energy consumption intensity; thirdly, agglomeration enables enterprises to communicate more closely with each other, which is conducive to the improvement of technological innovation and competitiveness, and thus promotes the continuous reduction of carbon 
emission intensity by relying on technological advance in respect to energy conservation and utilization (Moreno et al., 2014). However, for every 1\% increase in industrial concentration in Anhui Province, the carbon emission amount decrease by only $0.0045 \%$, which has the least influence among the 7 influencing factors, indicating that the industrial agglomeration in Anhui is not obvious and needed to be further strengthened.

\section{External investment and carbon emissions}

In respect to Anhui's utilization of out-of-province investment, the investment promotes the growth of carbon emissions, and every $1 \%$ rise in such investment will increase carbon emissions by $0.2484 \%$. In 2004, the country proposed a plan for the rise of Central China, and Anhui Province, which is at the intersection of Central and Eastern China, undertook a large number of industrial transfers from China's eastern coastal provinces. From 2005 to 2015, the annual growth rate of out-of-province investment in projects that were above 100 million yuan increased by an average of $31.52 \%$. In the initial stage, industrial projects were mainly introduced. For example, in 2007, the second industry accounted for $60.2 \%$ of the actual funds allocated to projects from outside the province with investment of more than 10 million yuan, and among the second production projects, 75.35 billion yuan was allocated to the manufacturing projects, accounting for $47.3 \%$ of the projects with investment of more than 10 million yuan. In the external investment of competitive industries in Anhui Province, the investment of power plant projects, steel product processing projects, coal chemical projects and other projects with high energy consumption accounted for $40 \%$ of the total investment. Over time, the investment structure of external capital has been optimized. In 2015, among the projects of over 100 million yuan using eternal capital, the growth rate of investment in the low-energy industries, such as modern service industry projects, electronic information projects, pharmaceutical industry projects and other tertiary industry projects was improved, but the secondary industry still accounted for $60.1 \%$ of the total investment, indicating that the transfer of external industries in Anhui Province is still dominated by the second industry, and the increase of carbon emission will continue.

Analysis from the perspective of FDI: FDI promotes the growth of carbon emission. For every $1 \%$ increase of FDI, carbon emission will increase by $0.1587 \%$, which is consistent with previous research. For example, Zhang et al. (2018) used data from 1982 to 2016 to conclude that the impact of FDI on China's carbon emissions is positive. Gong et al. (2018), based on STIRPAT model research, concluded that the increase of FDI would promote the growth of carbon emissions in the Yangtze River Delta region. Similarly, foreign investment in Anhui Province is still concentrated in traditional industries. For example, from 2000 to 2015, the manufacturing industry and the hydraulic and electric power industry of Anhui Province absorbed 67.19\% of FDI, and the carbon emissions of these two industries accounted for $78.16 \%$ of the industrial carbon emissions. FDI is mainly invested in industries with high carbon emissions. While stimulating local economy, it still has a large impact on carbon emissions.

\section{Economic openness and carbon emissions}

When many domestic and foreign scholars analyze the relationship between China's import and export trade and carbon emissions, most of them believe that China's 
foreign trade mode is also dominated by processing industries with high energy consumption and high pollution. Such a trade structure will result in more emissions as the proportion of China's exports increases. That is, the increase in export trade leads to the rise in carbon emissions, while the import trade will reduce carbon emissions. Anhui is a special case. Although its import and export trade is greater than import, its import and export trade is negatively correlated with carbon emissions, that is, for every $1 \%$ increase in the proportion of total import and export in total industrial output value, its carbon emission reduces by $0.0453 \%$. The main reason is that Anhui imports a large number of primary products and energy-consuming products, but when exporting, in addition to primary products, it also exports a certain number of high value-added products. On the contrary, in addition to high-tech products, Anhui's imports also include non-metal and chemical materials and other primary products (Table 7). However, objectively speaking, the import and export trade is very limited in reducing carbon emissions, reflecting the low level of regional industrial development.

Table 7. Comparison of some products of import and export trade in Anhui province in 2015 $\left(10^{4} \$\right)$

\begin{tabular}{|c|c|c|c|c|c|c|c|}
\hline Primary products & Exports & Imports & $\begin{array}{l}\text { Exports- } \\
\text { imports }\end{array}$ & Industrial product & Exports & Imports & $\begin{array}{l}\text { Exports- } \\
\text { imports }\end{array}$ \\
\hline Food and live animals & 90668 & 107868 & -17200 & Primary form of plastic & 12511 & 53645 & -41134 \\
\hline Meat and meat products & 600 & 7384 & -6784 & $\begin{array}{l}\text { Other chemical raw materials } \\
\text { and products }\end{array}$ & 13328 & 15991 & -2663 \\
\hline Dairy and egg products & 42 & 8348 & -8306 & Non-ferrous metal & 53624 & 71059 & -17435 \\
\hline Grain and its product & 7409 & 17934 & -10525 & pharmaceuticals & 20704 & 2241 & 18463 \\
\hline Vegetables and fruits & 23550 & 25565 & -2015 & $\begin{array}{c}\text { Machinery and transport } \\
\text { equipment }\end{array}$ & 1210348 & 224899 & 985449 \\
\hline $\begin{array}{l}\text { Feed (excluding unground } \\
\text { grain) }\end{array}$ & 1930 & 23683 & -21753 & $\begin{array}{l}\text { Power machinery and } \\
\text { equipment }\end{array}$ & 50990 & 20012 & 30978 \\
\hline Miscellaneous food & 16974 & 20996 & -4022 & Special industrial machinery & 306321 & 27507 & 278814 \\
\hline $\begin{array}{l}\text { Non-edible materials } \\
\text { (excluding fuels) }\end{array}$ & 36791 & 643688 & -606897 & $\begin{array}{c}\text { General industrial equipment } \\
\text { and parts }\end{array}$ & 170788 & 46999 & 123789 \\
\hline $\begin{array}{l}\text { Raw rubber (including } \\
\text { synthetic rubber and } \\
\text { recycled rubber) }\end{array}$ & 625 & 16173 & -15548 & $\begin{array}{l}\text { Telecom and voice recording } \\
\text { and playback equipment }\end{array}$ & 82498 & 2261 & 80237 \\
\hline Pulp and waste paper & 2152 & 51948 & -49796 & $\begin{array}{c}\text { Electrical machinery, } \\
\text { apparatus and its electrical } \\
\text { parts }\end{array}$ & 314048 & 36220 & 277828 \\
\hline $\begin{array}{l}\text { Natural fertilizers and } \\
\text { minerals (except coal, } \\
\text { petroleum and precious } \\
\text { stones) }\end{array}$ & 1870 & 2565 & -695 & $\begin{array}{c}\text { Road vehicles (including air } \\
\text { cushion) }\end{array}$ & 221586 & 2865 & 218721 \\
\hline Metal ore and metal waste & 46 & 528612 & -528566 & $\begin{array}{l}\text { Professional, scientific and } \\
\text { control equipment }\end{array}$ & 171277 & 69442 & 101835 \\
\hline $\begin{array}{l}\text { Coal, coke and coal } \\
\text { briquettes }\end{array}$ & 65 & 10521 & -10456 & Metalworking machinery & 12938 & 21286 & -8348 \\
\hline $\begin{array}{c}\text { Petroleum, petroleum } \\
\text { products and related raw } \\
\text { materials }\end{array}$ & 209 & 16900 & -16691 & $\begin{array}{c}\text { Office machinery and } \\
\text { automatic data processing } \\
\text { equipment }\end{array}$ & 25452 & 66913 & -41461 \\
\hline $\begin{array}{l}\text { Natural gas and man-made } \\
\text { gas }\end{array}$ & 130 & 768 & -638 & $\begin{array}{l}\text { Photographic equipment, } \\
\text { optical objects and clocks }\end{array}$ & 16631 & 17112 & -481 \\
\hline
\end{tabular}




\section{Conclusion}

Taking Anhui Province as an example, this paper calculates the industrial carbon emissions of Anhui Province by using the terminal energy consumption and social statistics data of different industries in the province from 2000 to 2015 . Through the expanded STIRPAT model, it analyzes the influencing factors of Anhui's carbon emissions in the context of industrial transformation. The research results show that:

(1) In respect to total carbon emission, Anhui's carbon emission increased steadily from 2000 to 2015 with an average annual growth rate of $10.50 \%$. In respect to growth rate, the average annual growth of carbon emission decreased to $4.29 \%$ from 2010 to 2015, indicating that Anhui's rapid growth momentum of carbon emission was restrained to some extent;

(2) In respect to carbon emissions of sub-sectors, the carbon emissions of mining industry, manufacturing industry and EGW from 2000 to 2015 showed an overall trend of growth. In respect to growth rate, it is shown as: mining industry > EGW > manufacturing industry. The proportion of carbon emission in the manufacturing industry shows a stable downward trend, while the proportion of EGW is relatively stable on the whole, and the proportion of the mining industry has been on the rise, showing a certain convergence on the whole and gradually showing a trend of "each accounting for $1 / 3$ share";

(3) According to the extended STIRPAT model analysis, 5 of the driving factors influencing the carbon emissions of Anhui Province from 2000 to 2015 are positively correlated, which is shown as: external investment > energy consumption structure > per capita income > proportion of the second industrial output in GDP > the amount of the actual use of foreign investment. The two factors, the proportion of total import and export in total industrial output value and the proportion of industrial added value above the scale in total industrial output value, are negatively correlated with total carbon emission, but the influence degree is far less than the other 5 factors;

(4) The relationship between Anhui Province's carbon emissions and economic development also shows an obvious inverted U-shaped curve. The carbon emission intensity of Anhui Province reached its peak in 2005, but per capita carbon emissions still kept increasing, indicating that a large number of foreign investment and traditional industries in the Yangtze River Delta region were transferred to Anhui from 2005 to 2015, leading to rapid industrial growth, and thus promoting the growth of carbon emissions;

(5) The energy consumption structure of Anhui Province has been dominated by coal for a long time, and external investment (including that from foreign countries, Hong Kong, Macao, Taiwan and other provinces) mainly invested in projects with high energy consumption, such as power plant projects, steel products processing projects and coal chemical projects, which are the main reasons for the sustainable growth of Anhui's carbon emissions. Although industrial agglomeration and import and export trade can reduce total carbon emissions, the impact is relatively low. Thus it can be seen that policy makers should pay more attention to the introduction of energy-saving and environmentally friendly enterprises when undertaking industrial transfer in Anhui Province, and actively control the increase of carbon emission by introducing technology and encouraging low-carbon technology.

In order to better reflect the spatial characteristics of industrial carbon emissions in Anhui Province, the next research should focus on the micro-level, pay attention to the changes of total carbon emissions and intensity of enterprises. 
Acknowledgements. This study was funding by the Fundamental Research Funds for the Central Universities under grant number 2018ZDPY07.

\section{REFERENCES}

[1] Auerbeck, D. R. (2001): $\mathrm{CO}_{2}$ emissions and $\mathrm{C}$ sequestration by agriculture - Perspectives and limitations. - Nutrient Cycling in Agroecosystems 60(1-3): 253-266.

[2] Bamminger, C., Poll, C., Marhan, S. (2018): Offsetting global warming-induced elevated greenhouse gas emissions from an arable soil by biochar application. - Global Change Biology 24(1): 318-334.

[3] Ban, Y. U., Jeong, J. H., Jeong, S. K. (2016): Assessing the performance of carbon dioxide emission reduction of commercialized eco-industrial park projects in South Korea. - Journal of Cleaner Production 114: 124-131.

[4] Cai, J. L., Yin, H., Varis, O. (2016): Impacts of industrial transition on water use intensity and energy-related carbon intensity in China: a spatio-temporal analysis during 20032012. - Applied Energy 183: 1112-1122.

[5] Cansino, J. M., Roman, M., Ordonez, M. (2016): Main drivers of changes in $\mathrm{CO}_{2}$ emissions in the Spanish economy: a structural decomposition analysis. - Energy Policy 89: $150-159$.

[6] Cellura, M., Longo, S., Mistretta, M. (2012): Application of the structural decomposition analysis to assess the indirect energy consumption and air emission changes related to Italian households consumption. - Renewable and Sustainable Energy Reviews 16(2): $1135-1145$.

[7] Chen, L., Xu, L. Y., Yang, Z. F. (2017): Accounting carbon emission changes under regional industrial transfer in an urban agglomeration in China's Pearl River delta. Journal of Cleaner Production 167: 110-119.

[8] Chen, S. Y., Jefferson, G. H., Zhang, J. (2011): Structural change, productivity growth and industrial transformation in China. - China Economic Review 22(1): 133-150.

[9] Chen, W. D., Yang, R. Y. (2018): Evolving temporal-spatial trends, spatial association, and influencing factors of carbon emissions in Mainland China: empirical analysis Based on provincial panel data from 2006 to 2015 . - Sustainability 10(8).

[10] Cheng, Z. H., Li, L. S., Liu, J., Zhang, H. M. (2018): Total-factor carbon emission efficiency of China's provincial industrial sector and its dynamic evolution. - Renewable and Sustainable Energy Reviews 94: 330-339.

[11] Deng, X. Z., Han, J. Z., Yin, F. (2012): Net energy, $\mathrm{CO}_{2}$ emission and land-based costbenefit analyses of Jatropha biodiesel: a case study of the Panzhihua Region of Sichuan Province in China. - Energies 5: 2150-2164.

[12] Feng, K. S., Davis, S. J., Sun, L. X., Li, X., Guan, D. B., Liu, W. D., Liu, Z., Hubacek, K. (2013): Outsourcing $\mathrm{CO}_{2}$ within China. - Proceedings of the National Academy of Sciences 110(28): 11654-11659.

[13] Griffin, P. W., Hammond, G. P., Norman, J. P. (2018): Industrial decarbonisation of the pulp and paper sector: a UK perspective. - Applied Thermal Engineering 134: 152-162.

[14] Guan, D. B., Klasen, S., Hubacek, K., Feng, K. S., Liu, Z., He, K. B., Geng, Y., Zhang, Q. (2014): Determinants of stagnating carbon intensity in China. - Nature Climate Change 4(11): 1017-1023.

[15] Jia, J. S., Gong, Z. H., Xie, D. M., Chen, J. H., Chen, C. D. (2018): Analysis of drivers and policy implications of carbon dioxide emissions of industrial energy consumption in an underdeveloped city: the case of Nanchang, China. - Journal of Cleaner Production 183: 843-857.

[16] Jiang, J. J., Ye, B., Xie, D. J., Tang, J. (2017): Provincial-level carbon emission drivers and emission reduction strategies in China: combining multi-layer LMDI decomposition with hierarchical clustering. - Journal of Cleaner Production 169: 178-190. 
[17] Jiang, X. T., Wang, Q., Li, R. R. (2018): Investigating factors affecting carbon emission in China and the USA: a perspective of stratified heterogeneity. - Journal of Cleaner Production 199: 85-92.

[18] Lebel, L., Garden, P., Banaticla, M. R. N., Lasco, R. D., Contreras, A., Mitra, A. P., Sharma, C., Nguyen, H. T., Sari, A. (2007): Integrating carbon management into the development strategies of urbanizing regions in Asia. - Journal of Industrial Ecology 11(2): 61-81.

[19] Li, A. J., Zhang, A. Z., Zhou, Y. X., Yao, X. (2017): Decomposition analysis of factors affecting carbon dioxide emissions across provinces in China. - Journal of Cleaner Production 141: 1428-1444.

[20] Li, J. B., Huang, X. J., Kwan, M. P., Yang, H., Chuai, X. W. (2018): The effect of urbanization on carbon dioxide emissions efficiency in the Yangtze River Delta, China. Journal of Cleaner Production 188: 38-48.

[21] Lin, B. Q., Moubarak, M. (2014): mitigation potential of carbon dioxide emissions in the Chinese textile Industry. - Applied Energy 113: 781-787.

[22] Lindner, S., Liu, Z., Guan, D. B., Geng, Y., Li, X. (2013): $\mathrm{CO}_{2}$ Emissions from China's power sector at the provincial level: consumption versus production perspectives. Renewable and Sustainable Energy Reviews 19: 164-172.

[23] Liu, B. Q., Chen, T., Li, Y. Q., Song, H. H., Ma, Z. X.(2018): Research on the effects of urbanization on carbon emissions efficiency of urban agglomerations in China. - Journal of Cleaner Production 197: 1374-1381.

[24] Liu, Z., Geng, Y., Lindner, S., Guan, D. B. (2012a): Uncovering China's greenhouse gas emission from regional and sectoral perspectives. - Energy 45: 1059-1068.

[25] Liu, Z., Geng, Y., Lindner, S., Zhao, H. Y., Fujita, T., Guan, D. B. (2012b): Embodied energy use in China's industrial sectors. - Energy Policy 49: 751-758.

[26] Liu, Z., Guan, D. B., Douglas, C. B., Zhang, Q., He, K. B., Liu. J. G. (2013): Energy policy: a low-carbon road map for China. - Nature 500(7461): 143-145.

[27] Liu, Z., Guan, D. B., Moore, S., Lee, H., Su, J., Zhang, Q. (2015): Steps to China' s carbon peak. - Nature 522(7556): 279-281.

[28] Lu, Q. L., Yang, H., Huang, X. J., Chuai, X. W., Wu, C. Y. (2015): Multi-sectoral decomposition in decoupling industrial growth from carbon emissions in the developed Jiangsu Province, China. - Energy. 82: 414-425.

[29] Malla, S. (2009): $\mathrm{CO}_{2}$ Emissions from electricity generation in seven Asia-Pacific and North American countries: a decomposition analysis. - Energy Policy 38(10): 6387-6387.

[30] Meng, L., Guo, J., Chai, J., Zhang, Z. K. (2011): China's regional $\mathrm{CO}_{2}$ emissions: characteristics, inter-regional transfer and emission reduction policies. - Energy Policy 39(10): 6136-6144.

[31] Mi, Z. F., Pan, S. Y., Yu, H., Wei, Y. M. (2015): Potential impacts of industrial structure on energy consumption and $\mathrm{CO}_{2}$ emission: a case study of Beijing. - Journal of Cleaner Production 103: 455-462.

[32] OECD (2003): Environmental Indicators-Development, Measurement and Use. - OECD, Paris.

[33] Olivier, J. G. J., Janssens-Maenhout, G., Muntean, M., Peters, J. A. H. W. (2015): Trends in Global $\mathrm{CO}_{2}$ Emissions: 2015 Report. - PBL Publishers, The Hague.

[34] Ouyang, X. L., Lin, B. Q. (2015): An analysis of the driving forces of energy-related carbon dioxide emissions in China's industrial sector. - Renewable and Sustainable Energy Reviews 45: 838-849.

[35] Rahman, M. M., Kashem, M. A. (2017): Carbon emissions, energy consumption and industrial growth in Bangladesh: empirical evidence from ARDL cointegration and granger causality analysis. - Energy Policy 110: 600-608.

[36] Ren, S. G., Yuan, B. L., Ma, X., Chen, X. H. (2014): The impact of international trade on China's industrial carbon emissions since its entry into WTO. - Energy Policy 69: 624634. 
[37] Shan, Y. L., Liu, J. H., Liu, Z., Xu, X. W. G., Shao, S. A., Wang, P., Guan, D. B. (2016): New provincial $\mathrm{CO}_{2}$ emission inventories in China based on apparent energy consumption data and updated emission factors. - Applied Energy 184: 742-750.

[38] Shao, S. A., Liu, J. H., Geng, Y., Miao, Z., Yang, Y. C. (2016a): Uncovering driving factors of carbon emissions from China's mining sector. - Applied Energy 166: 220-238.

[39] Shao, S. A., Yang, L. L., Gan, C. H., Cao, J. H., Geng, Y., Guan, D. B. (2016b): Using an extended LMDI model to explore techno-economic drivers of energy-related industrial $\mathrm{CO}_{2}$ emission changes: a case study for Shanghai (China). - Renewable and Sustainable Energy Reviews 55: 516-536.

[40] Song, M. L., Guo, X., Wu, K. Y., Wang, G. X. (2015): Driving effect analysis of energyconsumption carbon emissions in the Yangtze River delta region. - Journal of Cleaner Production 103: 620-628.

[41] Su, B., Huang, H. C., Ang, B. W., Zhou, P. (2010): Input-output analysis of $\mathrm{CO}_{2}$ emissions embodied in trade: the effects of sector aggregation. - Energy Economics 32(1): 166-175.

[42] Sun, L. C., Wang, Q. W., Zhou, P., Cheng, F. X. (2016a): Effects of carbon emission transfer on economic spillover and carbon emission reduction in China. - Journal of Cleaner Production 112: 1432-1442.

[43] Sun, Z. R., Luo, R. D., Zhou. D. Q. (2016b): Optimal path for controlling sectoral $\mathrm{CO}_{2}$ emissions among China's regions: a centralized dea approach. - Sustainability 8(1): 28.

[44] Tapio, P. (2005): Towards a theory of decoupling: degrees of decoupling in the EU and the case of road traffic in Finland between 1970 and 2001. - Transport Policy 12(2): 137151.

[45] Tian, X., Chang, M., Shi, F., Tanikawa, H. (2014): How does industrial structure change impact carbon dioxide emissions? A comparative analysis focusing on nine provincial regions in China. - Environmental Science and Policy 37: 243-254.

[46] Tian, X., Imura, H., Chang, M., Shi, F., Tanikawa, H. (2011): Analysis of driving forces behind diversified carbon dioxide emission patterns in regions of the mainland of China. - Frontiers of Environmental Science and Engineering in China 5: 445-458.

[47] Tian, X., Chang, M., Tanikawa, H., Shi, F., Imura, H. (2012): Regional disparity in carbon dioxide emissions: assessing sectoral impacts on the carbon dioxide emissions structure among regions of mainland China. - Journal of Industrial Ecology 16(4): 612622.

[48] Tian, Y. S., Xiong, S. Q., Ma, X. M., Ji, J. P. (2018): Structural path decomposition of carbon emission: a study of China's manufacturing industry. - Journal of Cleaner Production 193: 563-574.

[49] Waggoner, P. E., Ausubel, J. H. (2002): A framework for sustainability science: a renovated IPAT identity. - Proceedings of the National Academy of Sciences 99: 78607885.

[50] Wang, C. J., Wang, F., Zhang, H. G., Ye, Y. Y., Wu, Q., Su, Y. X. (2014a): Carbon Emissions decomposition and environmental mitigation policy recommendations for sustainable development in Shandong Province. - Sustainability 6(11): 8164-8179.

[51] Wang, H. K., Zhang, Y. X., Lu, X., Nielsen, C. P., Bi, J. (2015a): Understanding China's carbon dioxide emissions from both production and consumption perspectives. Renewable and Sustainable Energy Reviews 52: 189-200.

[52] Wang, W. W., Liu, X., Zhang, M., Song, X. F. (2014b): Using a new generalized LMDI (logarithmic mean divisia index) method to analyze China's energy consumption. Energy 67: 617-622.

[53] Wang, Z., Zhao, L., Mao, G. Z., Wu, B. (2015b): Eco-efficiency trends and decoupling analysis of environmental pressures in Tianjin, China. - Sustainability 7: 15407-15422.

[54] Wang, Z. H., Yang, L. (2015c): Delinking indicators on regional industry development and carbon emissions: Beijing-Tianjin-Hebei economic band case. - Ecological Indicators 48: 41-48. 
[55] Wang, S. J., Ma, Y. Y. (2018a): Influencing factors and regional discrepancies of the efficiency of carbon dioxide emissions in Jiangsu, China. - Ecological Indicators 90: 460468.

[56] Wang, Y., Yang, G. C., Dong, Y., Cheng, Y., Shang, P. P. (2018b): The Scale, structure and influencing factors of total carbon emissions from households in 30 provinces of China-based on the extended STIRPAT model. - Energies 11(5).

[57] Wang, Z. H., Li, Y. M., Cai, H. L., Wang, B. (2018c): Comparative analysis of regional carbon emissions accounting methods in China: production-based versus consumptionbased principles. - Journal of Cleaner Production 194: 12-22.

[58] Xian, Y. J., Wang, K., Shi, X. P., Zhang, C., Wei, Y. M., Huang, Z. M. (2018): Carbon emissions intensity reduction target for China's power industry: an efficiency and productivity perspective. - Journal of Cleaner Production 197: 1022-1034.

[59] Xiao, B. W., Niu, D. X., Guo, X. D. (2016): The driving forces of changes in $\mathrm{CO}_{2}$ emissions in China: a structural decomposition analysis. - Energies 9(4): 259-276.

[60] Xu, S. C., He, Z. X., Long, R. Y., Chen, H., Han, H. M., Zhang, W. W. (2016): Comparative analysis of the regional contributions to carbon emissions in China. Journal of Cleaner Production 127: 406-417.

[61] Yan, X., Fang, Y. P. (2015): $\mathrm{CO}_{2}$ emissions and mitigation potential of the Chinese manufacturing industry. - Journal of Cleaner Production 103: 759-773.

[62] Yang, L. X., Xia, H., Zhang, X. L., Yuan, S. F. (2018b): What matters for carbon emissions in regional sectors? A China study of extended STIRPAT model. - Journal of Cleaner Production 180: 595-602.

[63] Yang, S. G., Cao, D., Lo, K. (2018a): Analyzing and optimizing the impact of economic restructuring on Shanghai's carbon emissions using STIRPAT and NSGA-II. Sustainable Cities and Society 40: 44-53.

[64] Yang, Z. W., Liu, H. L., Xu, X. Y., Yang, T. T. (2016): Applying the water footprint and dynamic structural decomposition analysis on the growing water use in China during 1997-2007. - Ecological Indicators 60: 634-643.

[65] York, R., Rosa, E. A., Dietz, T. (2003): STIRPAT, IPAT and ImPACT: analytic tools for unpacking the driving forces of environmental impacts. - Ecological Economics 46(3): 351-365.

[66] Yu, Y. D., Chen, D. J., Zhu, B., Hu, S. Y. (2013): Eco-efficiency trends in China, 19782010: decoupling environmental pressure from economic growth. - Ecological Indicators 24: $177-184$.

[67] Yuan, Z. W., Shi, L. (2009): Improving enterprise competitive advantage with industrial symbiosis: case study of a smeltery in China. - Journal of Cleaner Production 17: 12951302.

[68] Zhang, M., Wang, W. W. (2013): Decouple indicators on the $\mathrm{CO}_{2}$ emission-economic growth linkage: the Jiangsu Province case. - Ecological Indicators 32: 239-344.

[69] Zhang, P. Y., He, J. J., Hong, X., Zhang, W., Qin, C. Z., Pang, B., Li, Y. Y., Liu, Y. (2017): Regional-level carbon emissions modelling and scenario analysis: a STIRPAT case study in Henan Province, China. - Sustainability 9(12).

[70] Zhang, Y., Fang, G. (2013): Research on Spatial-temporal characteristics and affecting factors decomposition of agricultural carbon emission in Suzhou City, Anhui Province, China. - Applied Mechanics and Materials 291: 1385-1388.

[71] Zhang, Y., Zhang, S. F. (2018): The impacts of GDP, trade structure, exchange rate and FDI inflows on China's carbon emissions. - Energy Policy 120: 347-353.

[72] Zhang, Y. J., Da, Y. B. (2015): The decomposition of energy-related carbon emission and its decoupling with economic growth in China. - Renewable and Sustainable Energy Reviews 41: 1255-1266.

[73] Zhang, Y. X., Wang, H. K., Liang, S., Xu, M., Liu, W. D., Li, S. L., Zhang, R. R., Chris, P. N., Bi, J. (2014a): Temporal and spatial variations in consumption-based carbon dioxide emissions in China. - Renewable and Sustainable Energy Reviews 40: 60-68. 
[74] Zhang, Z. K., Guo, J., Geoffrey, J. D. H. (2014b): The effects of direct trade within China on regional and national $\mathrm{CO}_{2}$ emissions. - Energy Economics 46: 161-175.

[75] Zhao, M., Tan, L., Zhang, W., Ji, M., Liu, Y., Yu, L. (2010): Decomposing the influencing factors of industrial carbon emissions in Shanghai using the LMDI method. Energy 35(6): 2505-2510.

[76] Zhao, X. F., Li, H. N., Wu, L., Qi, Y. (2014): Implementation of energy-saving policies in China: how local governments assisted industrial enterprises in achieving energysaving targets. - Energy Policy 66: 170-184.

[77] Zhao, X. R., Zhang, X., Li, N., Shao, S. A., Geng, Y. (2017): Decoupling economic growth from carbon dioxide emissions in China: a sectoral factor decomposition analysis. - Journal of Cleaner Production 142: 3500-3516.

[78] Zhou, D. Q., Zhou, X. Y., Xu, Q., Wu, F., Wang, Q. W., Zha, D. L. (2018): Regional embodied carbon emissions and their transfer characteristics in China - Structural Change and Economic Dynamics 46: 180-193.

[79] Zhou, X. Y., Zhang, J., Li, J. P. (2013): Industrial structural transformation and carbon dioxide emissions in China. - Energy Policy 57: 43-51. 